\title{
ASSESSING CLIMATE CHANGE EXPOSURE OF RURAL FRESH WATER AND SANITATION - A CASE STUDY IN CANGIO DISTRICT
}

\author{
Ngoc Tuan Le $e^{1, *}$, Xuan Hoang Tran ${ }^{2}$ \\ ${ }^{1}$ University of Science - Vietnam National University Ho Chi Minh City, \\ 227 Nguyen Van Cu Street, Ward 4, District 5, HCMC \\ ${ }^{2}$ Institute of Meteorology Hydrology Oceanology and Environment, \\ 60 Nguyen Dinh Chieu street, Da Kao Ward, District 1, HCMC \\ "Email:Intuan@hcmus.edu.vn
}

Received: 1 November 2016; Accepted for publication: 13 November 2017

\begin{abstract}
By index method associated with professional adjustment, analytic hierarchy process (AHP), data collection, and GIS methods, the study aimed to assess climate change (CC) exposure (E) of rural fresh water and sanitation (RFWS) via 7 indicator groups (including temperature, precipitation, wind, saltwater intrusion -SI, drought, riverbank landslide, and inundation), a case study in Can Gio district (Ho Chi Minh city) in the period of 2015-2025.

Exposure indices to CC of RFWS in Can Gio district would be almost at medium-low levels $(E=33-53)$ and tend to increase gradually from the infield to riverside areas, from land to sea. The highest E distributed in Thanh An, Long Tau riverside, and Phu Loi island. Some locations, having low E index but located in residential areas with plenty of infrastructures, could be more vulnerable, such as Nha Be riverside (Binh Khanh), Dong Dinh outfall, Tac Suot wharf (in Mieu Nhi, Mieu Ba -Can Thanh town), and Soai Rap riverside (Ly Nhon), and thus need taking into concerns.
\end{abstract}

Keywords: climate change, rural fresh water and sanitation, exposure index.

Classification numbers: $3.5 ; 3.8$.

\section{INTRODUCTION}

Climate change (CC) is a major challenge for humanity in the $21^{\text {st }}$ century. The increase in risks of CC and disasters (such as inundation, saltwater intrusion, etc.) has led to the increase in vulnerability of livelihoods, living standard, etc., especially in rural areas where socio-economic activities mainly depend on natural resources. Besides, rural fresh water and sanitation (RFWS) is a basic demand and play an important role in the daily life. Statistics show about $80 \%$ of disease cases in Vietnam have been caused by water pollution [1]. It accordingly results in the pressure on RFWS in particular and public health in general in the context of CC and disasters [2 $-5]$. 
Can Gio is a coastal district in Ho Chi Minh City, has 32 water supply stations: 27 water supply satellites in the form of socialization and the rest 05 of retail changers serving the scattered population. In general, it is difficult in using clean water in Can Gio, some water supply satellites have not met water demand of citizen, the supply time is still limited, only some stations are fulltime operated, etc. [6 - 8]. Recent studies have indicated the risk of serious impacts due to CC and sea level rise in Can Gio [9, 10]. However, there has been no in-depth study on RFWS in the context of CC, especially assessing the vulnerability of this sector.

Accordingly, the study aimed to assess the exposure level to CC of RFWS, a case study in Can Gio, under high greenhouse gas emission scenario (A1FI) at different points of time (current, 2020, and 2025) by index method, forwarding to assess the vulnerability due to CC considered in the relationship among exposure (E), sensitivity (S) and adaptive capacity (AC) of the system [11]. The results could play a very important role of planning appropriate adaptive policies, strategies, and measures in each specific condition, contributing to minimization of risks and ensurement of the sustainable development.

\section{METHODS}

\subsection{Description of study site}

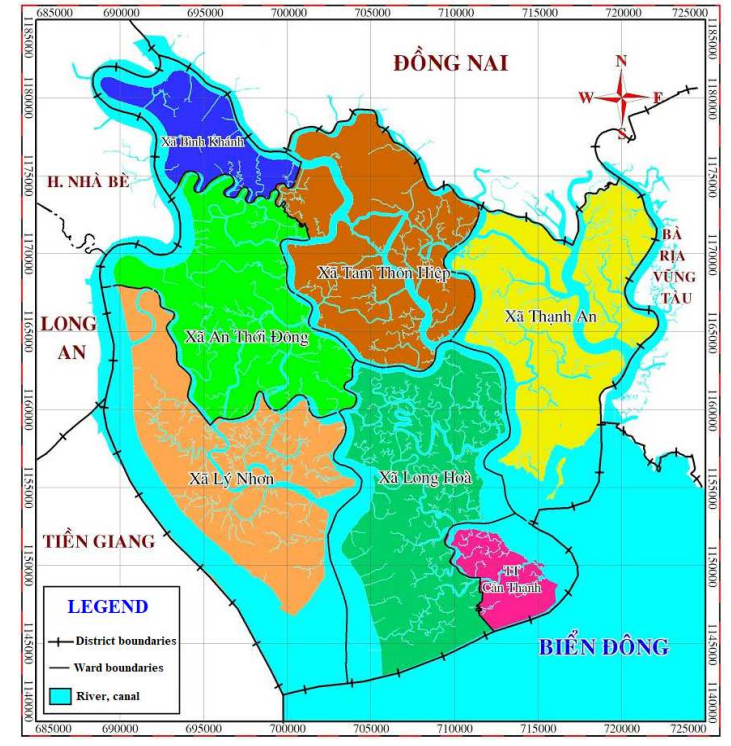

Figure 1. Map of Can Gio district.

Can Gio is a coastal suburban district of HCMC, located $50 \mathrm{~km}$ from the city center, bordered by Nha Be district in the north, Long An and Tien Giang provinces in the west, Dong Nai province in the northeast, Ba Ria - Vung Tau province in the southeast, and the East Sea in the south (Figure 1). Can Gio district includes Can Thanh town and six communes (Binh Khanh, An Thoi Dong, Tam Thon Hiep, Thanh An, Ly Nhon, and Long Hoa). They were areas considered and assessed in this research.

\subsection{Index method}

Can Gio is a coastal suburban district of HCMC, located $50 \mathrm{~km}$ from the city center, bordered by Nha Be district in the north, Long An and Tien Giang provinces in the west, Dong Nai province 72 
in the northeast, Ba Ria - Vung Tau province in the southeast, and the East Sea in the south (Figure 1). Can Gio district includes Can Thanh town and six communes (Binh Khanh, An Thoi Dong, Tam Thon Hiep, Thanh An, Ly Nhon, and Long Hoa). They were areas considered and assessed in this research.

This method was used to assess E to CC of RFWS. The process is as follows:

- Identifying E indicators: was carried out by the professional adjustment method.

- Determining weights of indicators: was conducted by experts in conjunction with $A H P$ method. Different indicators have different role (importance), therefore, their weights should be determined to be more precise in calculation and assessment. There were (a) weight of each variable (indicator) and (b) weight of each indicator group. Priority weight $=(a) *(b)($ Table 2$)$.

- Collecting and calculating related figures: by data collection method, related document and data were selected and then standardized to the scale of 0-100 [12]. In this study, the standardization was performed from the interpolation results (raster) on ArcGIS 10.2 using the tool Raster Calculator

- Calculating E index: E index was calculated based on the standardized value of subvariables $\mathrm{E}_{i}$ and weights $\mathrm{w}_{\mathrm{E} i}$. The $\mathrm{E}$ index was divided into 4 levels to compare and evaluate among considered communes (Table 1).

- Mapping, analysis and evaluation: GIS was used to establish related maps.

Table 1. Assessment scale of exposure level.

\begin{tabular}{|c|c|c|c|c|}
\hline Value & $\mathbf{0 - 2 5}$ & $\mathbf{2 5 - 5 0}$ & $\mathbf{5 0 - 7 5}$ & $\mathbf{7 5 - 1 0 0}$ \\
\hline Describe & Low exposure & $\begin{array}{c}\text { Medium - low } \\
\text { exposure }\end{array}$ & $\begin{array}{c}\text { Medium }- \text { high } \\
\text { exposure }\end{array}$ & High exposure \\
\hline
\end{tabular}

\subsection{Professional adjustment and AHP methods}

Professional adjustment method was applied in conjunction with the AHP to identify E indicators and their weights. 32 experts from 17 prestigious universities, institutes, environmental and CC research centers participated in the survey. Results of the survey were synthesized by the geometric an average method. Consistency was checked via consistency ratio

where $\mathrm{CI}$ is consistency index:

$$
(\mathrm{CR}): C R=\frac{C l}{R l}
$$

$$
\begin{aligned}
& C I=\frac{\lambda \max -n}{n-1} \\
& \lambda_{\max }=\frac{1}{n} \cdot \frac{\sum_{j=1}^{n} a_{i j} \cdot w_{j}}{w_{1}}
\end{aligned}
$$

$\mathrm{a}_{\mathrm{ij}}$ : the priority value of variable in comparison matrix, $\mathrm{w}_{\mathrm{j}}$ : weight of the $\mathrm{j}$ variable, $\mathrm{n}$ : the number of variables; RI (Random Index) ranged from 0.58 to 1.49 corresponding to the number of variables from 3 to 10 [13]. Consistency is assured when $\mathrm{CR} \leq 10 \%$.

\subsection{Data collection}

This method was applied to collect documents and data of meteorology, hydrology, landslides, current status and simulating results of inundation and salinisation, etc. in research areas serving calculation and evaluation. 
- Daily temperature data (max, min, average) at Tan Son Hoa, Bien Hoa, Vung Tau, and My Tho stations in the period of 1978-2015.

- Daily precipitation data at Tan Son Hoa, Nha Be, Can Gio, Tam Thon Hiep, Cat Lai, Le Minh Xuan, Vung Tau, and My Tho stations in the period of 1980-2015.

- Daily average and the highest wind speed data at the Tan Son Hoa, Bien Hoa, Vung Tau, and My Tho stations in the period of 1978-2015.

- The simulation results of inundation [14] and SI [15] in the context of CC (high greenhouse gas emission scenario A1FI was considered) in the local.

\subsection{GIS method}

ArcGIS 10.2 and Map Info 11.0 was used to exploit the data, standardize, calculate synthetic indices and mapping to visualize the calculation results. Besides, the Inverse Distance to a Power method was applied to calculate E index in different areas within the study scope on the basis of statistics data and simulation results at the calculation nodes. The Surfer 10.0 software and a fixed radius of $1 \mathrm{~km}$ were applied.

\section{RESULTS AND DISCUSSION}

\subsection{Indicators and weights}

Table 2. Indicators and weights.

\begin{tabular}{|c|c|c|c|c|c|}
\hline Group & Indicator & Code & Weight & \begin{tabular}{|c|}
$\begin{array}{l}\text { Weight of } \\
\text { group }\end{array}$ \\
\end{tabular} & $\begin{array}{l}\text { Priority } \\
\text { weight }\end{array}$ \\
\hline \multirow{5}{*}{$\begin{array}{c}\text { E.nd } \\
\text { (temperature) }\end{array}$} & Min temperature evolution & E.nd.1 & 0.159 & \multirow{5}{*}{0.166} & 0.026 \\
\hline & Max temperature evolution & E.nd.2 & 0.320 & & 0.053 \\
\hline & Average temperature evolution & E.nd.3 & 0.148 & & 0.024 \\
\hline & Annual amplitude of average temperature & E.nd.4 & 0.136 & & 0.022 \\
\hline & The number of hot days (over $35^{\circ} \mathrm{C}$ ) per year & E.nd.5 & 0.238 & & 0.040 \\
\hline \multirow{4}{*}{$\begin{array}{l}\text { E. } \operatorname{lm} \\
\text { (precipitation) }\end{array}$} & Annual precipitation evolution & E.lm.1 & 0.240 & \multirow{4}{*}{0.141} & 0.034 \\
\hline & Rainy season precipitation evolution & E.lm.2 & 0.243 & & 0.034 \\
\hline & Dry season precipitation evolution & E. $\operatorname{lm} .3$ & 0.263 & & 0.037 \\
\hline & $\begin{array}{l}\text { The number of heavy rainy days (> } 50 \\
\text { mm/day) per year }\end{array}$ & E.lm.4 & 0.254 & & 0.036 \\
\hline E.g (wind) & Max wind speed & E.g & 1 & 0.129 & 0.129 \\
\hline \multirow{4}{*}{$\begin{array}{c}\text { E.xnm } \\
\text { (saltwater } \\
\text { intrusion) }\end{array}$} & Max salinity & E.xnm.1 & 0.297 & \multirow{4}{*}{0.170} & 0.051 \\
\hline & \begin{tabular}{|lllll}
$\begin{array}{l}\text { Duration of } \\
\text { (changeable) }\end{array}$ & salinity & above & 18 & $\% o^{*}$ \\
\end{tabular} & E.xnm.2 & 0.197 & & 0.034 \\
\hline & \begin{tabular}{|lllll}
$\begin{array}{l}\text { Duration of } \\
\text { (changeable) }\end{array}$ & salinity above $30 \% o^{*}$ \\
\end{tabular} & E.xnm.3 & 0.339 & & 0.058 \\
\hline & Salinity amplitude of the saltiest month & E.xnm.4 & 0.167 & & 0.028 \\
\hline \multirow{4}{*}{$\begin{array}{c}\text { E.ng } \\
\text { (Inundation) }\end{array}$} & Inundation area & E.ng.1 & 0.356 & \multirow{4}{*}{0.160} & 0.057 \\
\hline & Inundation depth & E.ng.2 & 0.184 & & 0.029 \\
\hline & Inundation duration & E.ng.3 & 0.231 & & 0.037 \\
\hline & The number of inundation per year & E.ng.4 & 0.229 & & 0.037 \\
\hline E.sl (landslides) & Landslide speed & E.sl & 1 & 0.103 & 0.103 \\
\hline E.hh (drought) & Drought index & E.hh & 1 & 0.131 & 0.131 \\
\hline
\end{tabular}

* the values were chosen due to the characteristics of the local (coastal area) 
By professional adjustment and AHP methods, indicators and weights for assessing exposure levels to CC of RFWS were established as in Table 2. As mentioned, each indicator or each group has its own importance in the relationship with ability of exposure to CC. Table 2 showed the indicator groups significantly affected E index would be SI, temperature, and inundation.

\subsection{E index to some meteorological factors}

E index to temperature (E.nd): Based on 5 indicators, E.nd maps were built and shown in Figure 2. E.nd in Can Gio would increase from the sea to the mainland where the highest and lowest values would be in Binh Khanh (about 70) and Can Thanh (about 25), respectively. There is no significant change in the period of 2015 - 2025, consistent with the general trend of temperature.

E index to precipitation (E.Im): Results showed that the highest E.Im was in Tam Thon Hiep (E.lm = 65), followed by An Thoi Dong (62.3), Binh Khanh (59.2), Can Thanh (58.5), and Thanh An (50.2). To 2025, E.lm in Can Gio district tends to decrease, but not significant as compared to that in 2015.

$\boldsymbol{E}$ index to wind $(\boldsymbol{E} . \mathrm{g})$ : the max wind speed tends to increase in the north and north-east, but decrease in the south-west. With the max wind speeds of 23-28 m/s, E.g in the investigated area would be about 25-75, mostly at medium-high level (50-75), excepting for a part of Ly Nhon $($ E.g $=25-50)$.

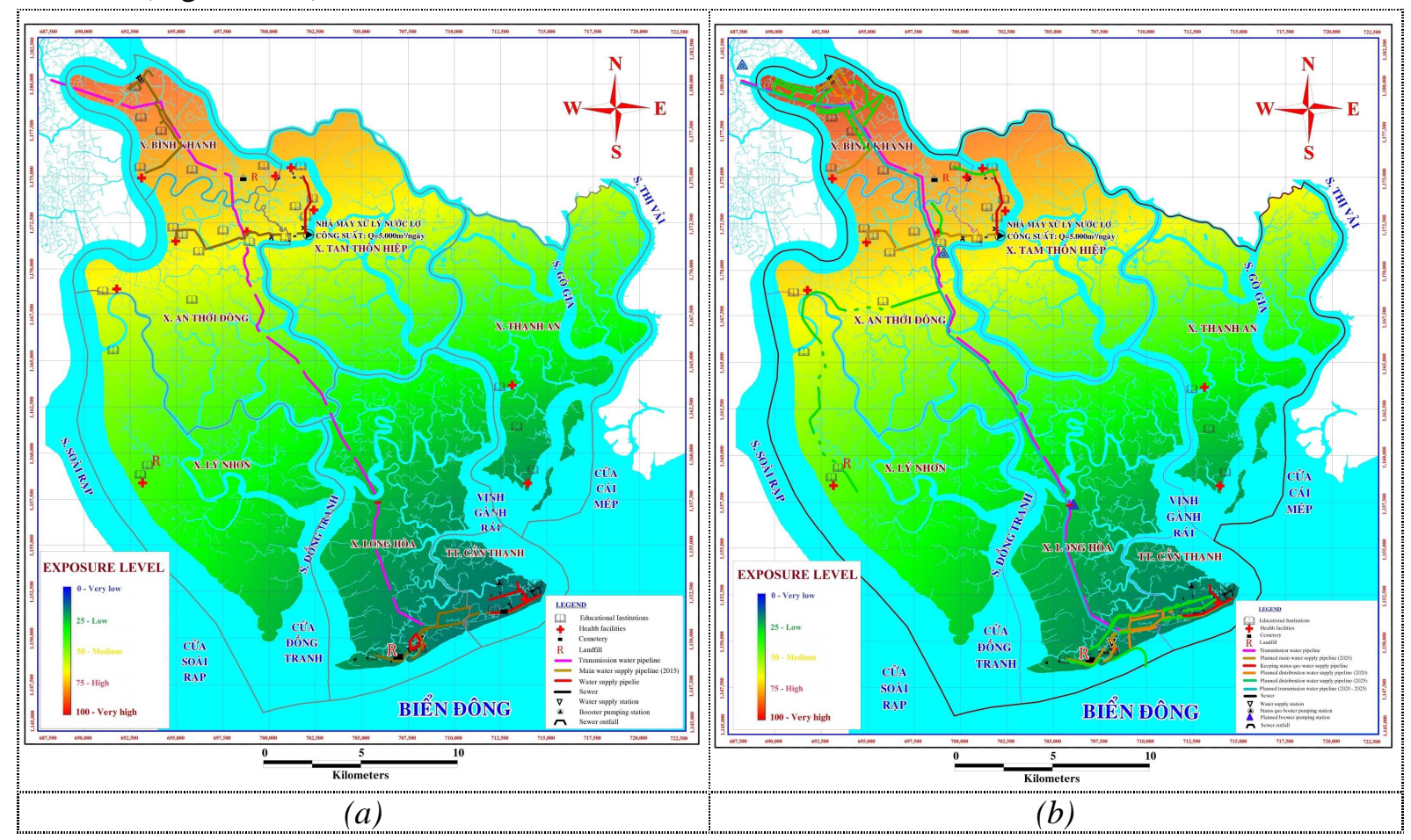

Figure 2. E.nd maps in Can Gio: (a) 2015, (b) 2025.

\section{3. $E$ index to some natural disasters}

E index to saltwater intrusion (E.xnm): Figure 3a showed E.xnm in Can Gio was relatively high (58.2) and tend to descend from the sea to the mainland. The highest one was at 
Long Tau outfall, Soai Rap, Dong Tranh, and Thi Vai rivers corresponding to Can Thanh (76.2), Long Hoa (74.1), Ly Nhon (68.1), and Thanh An (60.5). For RFWS sector, a high E.xnm reflects significant impacts (both in terms of water quality and water supply infrastructure), consequently, water supply for the local in fact must be transferred from the city center. To 2025, the E.xnm would increase but not significant (Figure 3b).

E index to drought (E.hh): Results showed E.hh in Can Gio tended to increase from the inland to the sea - consistent with the trend of precipitation variation (descending to the sea). Differences among areas were relatively small. Based on the assessment scale of drought index: $<0.5$ (very wet), 0.5-1.0 (moist), 1.0-2.0 (slightly dry), 2.0-4.0 (dry) and > 4.0 (very dry), E.hh in Can Gio was standardized to 0, 25, 50, 75, 100, respectively. In 2015, E.hh ranged from 25-75 (corresponding to medium-low to medium-high level). It would not much increase till 2025 due to the increase in temperature and insignificant change in precipitation.

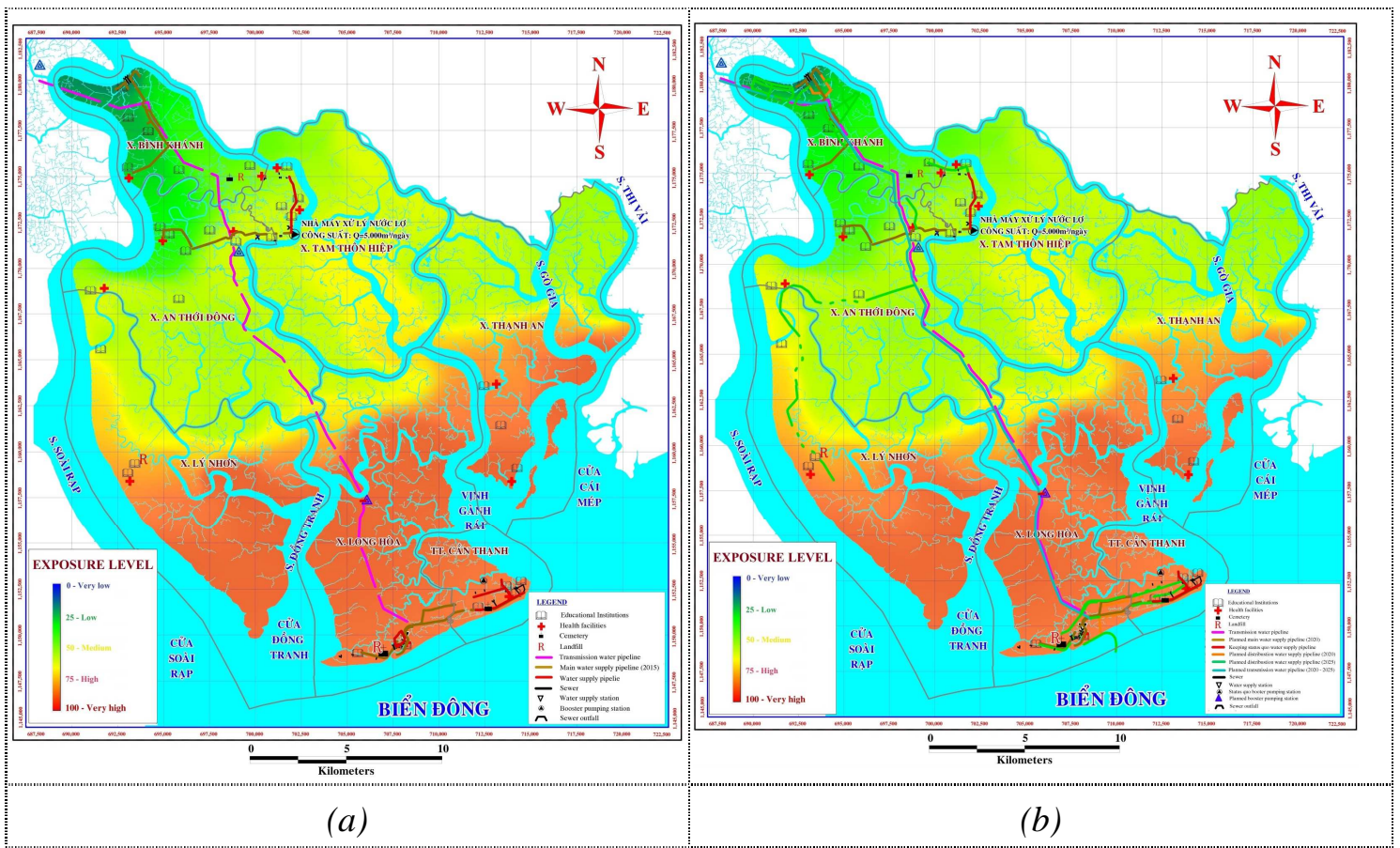

Figure 3. E.xnm maps in Can Gio: (a) 2015; (b) 2025.

E index to risk of landslide (E.sl): Riverbank landslide speed in Can Gio in the period of 1989 - 2015 ranged from 0-20 m/year. E index is then standardized to 0-100. Thereby, serious landslide areas were located along Long Tau river, the right bank of Soai Rap river, and Nha Be river. Phu Loi island (Thanh An commune) has the highest landslide speed; inversely, a slow one had been recorded in the coastal of Can Thanh due to coastal embankment system. It should be thus taken into consideration for infrastructures located in high risk areas of landslide.

$\boldsymbol{E}$ index to inundation (E.ng): with relatively smooth terrain and homogeneous hydrological conditions, most communes in Can Gio have relatively evenly E.ng (Figure 4): the highest value (up to 61) was in riparian areas of Go Gia river, Thi Vai river (Thanh An commune); E.ng of the remaining communes were in the range of very low to low level (0-25); riparian areas had higher E.ng than the inland did. Most of areas having high E.ng are mangrove forest, impacts of inundation are thus in fact insignificant. In contrast, some areas having lower E.ng but should be taken into consideration in relation to the socio-economic conditions: 
- Areas along Ganh Rai bay -from Dong Dinh outfall to Tac Suat wharf (in Mieu Nhi, Mieu Ba commune - Can Thanh) have low E.ng (around 25), but face to greater risks due to high population density as well as economic activities.

- Thanh Hoa is one of areas having very low E.ng in Thanh An commune, but located in commune center, therefore related impacts would be higher.

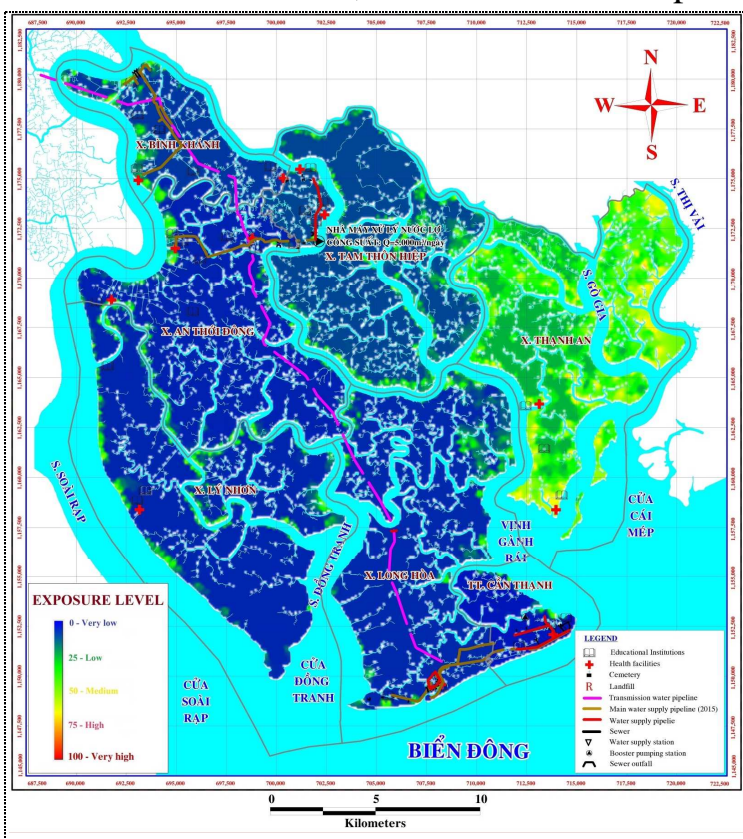

(a)



(b)

Figure 4. E.ng maps in Can Gio: (a) 2015; (b) 2025.

\subsection{Synthetic $E$ index to climate change (E)}

Based on 7 indicator groups as mentioned, the synthetic exposure index to CC of RFWS in Can Gio was calculated and shown in Figure 5, then detailed in the range of 30-50 and presented in Figure 6. Results showed E index was at medium-low level (from 33.13 to 51.70). With the relatively short considered duration (2014-2025), CC manifestations should not be really clear, there is thus no significant difference in $\mathrm{E}$ index by the time. $\mathrm{E}$ index to CC of RFWS would be higher in riverside as well as water front areas and tend to decrease into the inland.

Long Tau outfall (Thanh An commune), Thi Vai river, and Phu Loi island had high E indices, mainly due to inundation, landslide, and SI; followed by the north of Tam Thon Hiep and Binh Khanh, mainly due to strong wind, temperature, and rainfall; and then several riverside areas in Binh Khanh, Nhon Ly, and Can Thanh due to effects of landslide and inundation.

Figure 6 indicated areas being difficult to access water supply sources such as Thanh An commune and area along Soai Rap river (Ly Nhon commune) having relatively high E (over 40). The water supply infrastructures are mostly located in Binh Khanh and Can Thanh while E index in Can Thanh was relatively high (over 40), consequently works here could be more affected than those in other areas. Besides, there are 3 landfills located in Can Gio district (in Ly Nhon, Binh Khanh, and Can Thanh). Two of them (in Binh Khanh and Can Thanh) are located in relatively high exposed areas (over 40), therefore need taking into consideration. 


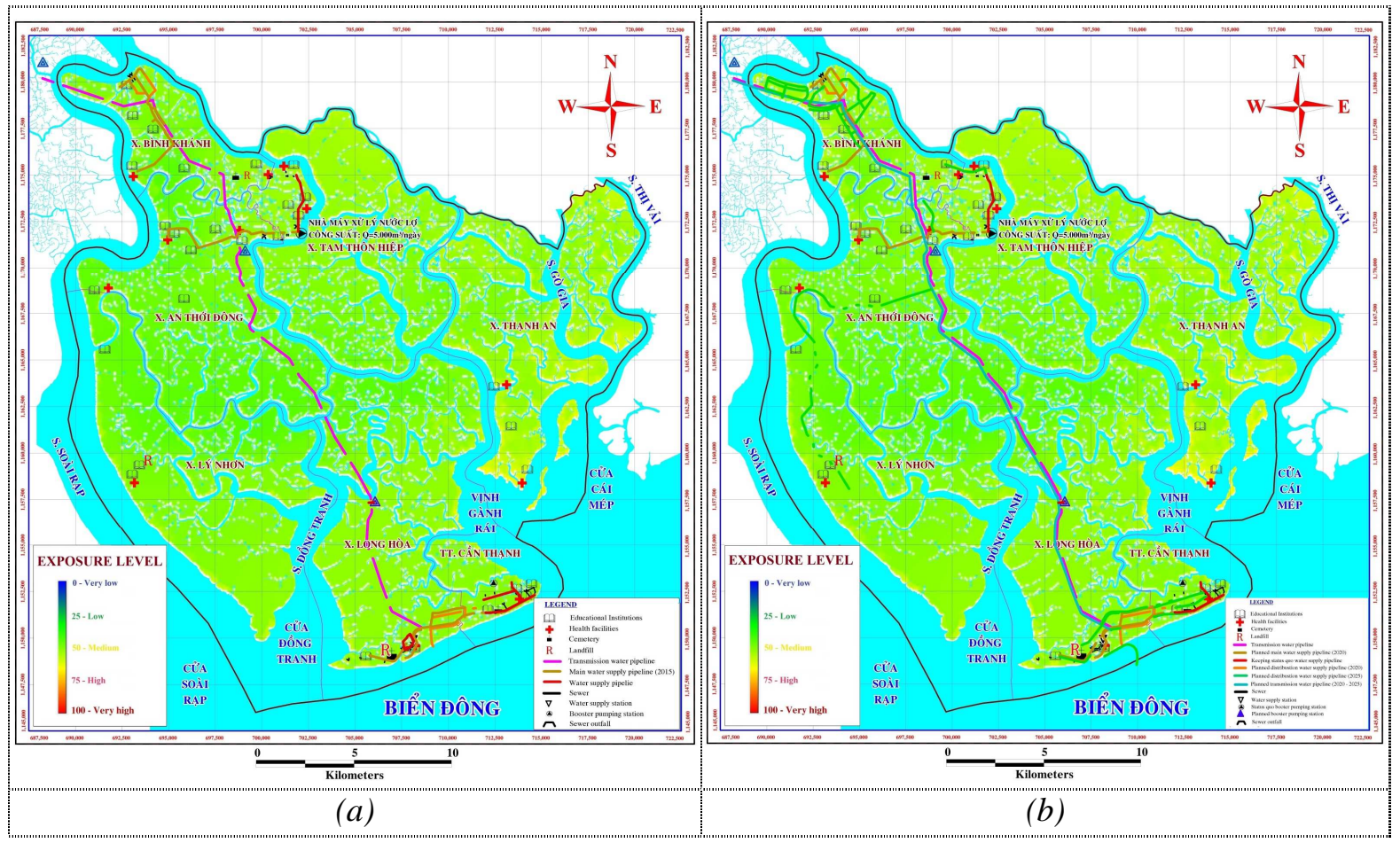

Figure 5. E index maps in Can Gio (ranging in 0-100): (a) 2015, (b) 2025.

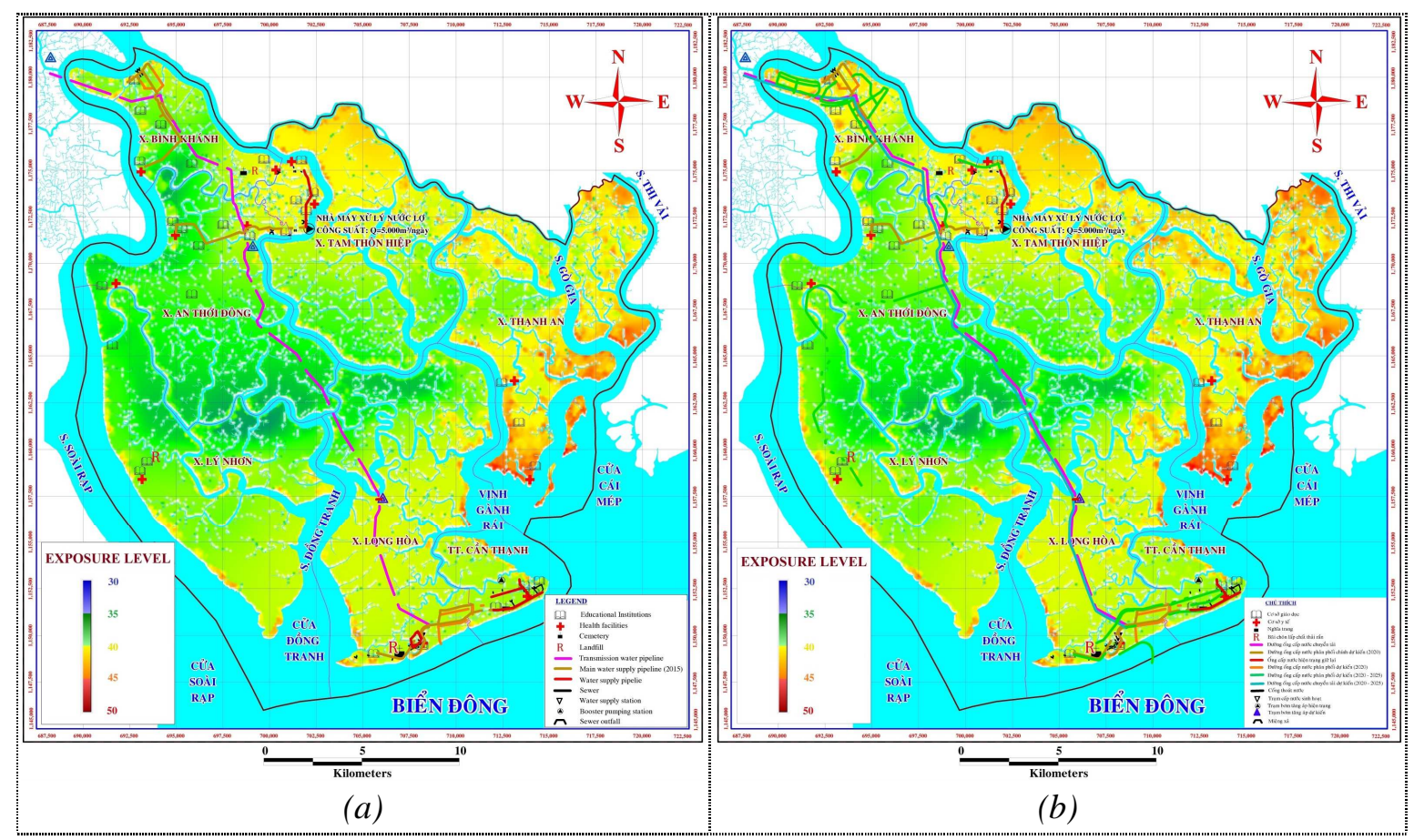

Figure 6. E index maps in Can Gio (ranging in 30-50): (a) 2015, (b) 2025.

\section{CONCLUSIONS}

The study aims to assess CC exposure of RFWS in Can Gio by index method with 20 indicators divided into 07 main groups: temperature, precipitation, wind, saltwater intrusion, 78 
drought, landslides and inundation. Results were demonstrated through maps, thereby: E index to CC of RFWS in Can Gio was at medium-low level (33.1 - 51.7), no significant increase till 2025 (33.4 - 52.6). In general, E index would be higher in riverside and water front areas, and decrease into the inland. The concern areas include (i) Thanh An (Long Tau outfall, Thi Vai river, and Phu Loi island) with risks of inundation, landslide, and SI; (ii) the north of Tam Thon Hiep and Binh Khanh with risks of strong wind, temperature, precipitation; (iii) several riverside areas in Binh Khanh, Ly Nhon, and Can Thanh affected by landslide and inundation. Accordingly, in order to mitigate the vulnerability to CC of this sector, it is necessary to assess the sensitivity and adaptive capacity, providing the basis to identify adaptation demands and to propose appropriate management solutions.

Acknowledgement. This research is funded by Vietnam National University Ho Chi Minh City (VNUHCM) under grant number C2016-18-15.

\section{REFERENCES}

1. Bureau of Medical Environmental Management (BMEM) - The report of assessing water supply and sanitation in Vietnam in 2011 (in Vietnamese), 2012.

2. Doan T. H. - Assessing vulnerability due to climate change to rural water supply in Mekong Delta (in Vietnamese). Journal of Water resources and Environmental Engineering 46 (2014) 34-40.

3. Luong V. A., Pham T. M. T., Nguyen T. L. - Study and proposal of suitable solutions for rural water supply in the context of climate change in Nam Dinh. (in Vietnamese) Engineering science in Irrigation and Environment 45 (6) (2014) 69-75.

4. Laurie J. Van Leuven - Chapter 2: Water/Wastewater Infrastructure Security: Threats and Vulnerabilities. Handbook of Water and Wastewater Systems Protection, 2011.

5. WHO - The resilience of water supply and sanitation in the face of climate change, 2009.

6. Ho Chi Minh City People's Committee - Decision No. 4766/QD-UBND on the approval of the scheme on adjusting the general planning on construction of Can Gio district, Ho Chi Minh City (in Vietnamese), 2012.

7. Can Gio district People's Committee - Results of implementing the program of new rural construction in CanGio district in the period of 2010 - 2015 and the tasks for the period of 2016-2020 (in Vietnamese), 2015.

8. Can Gio District People's Committee - Planning for water supply in CanGio district 2016 (in Vietnamese), 2016.

9. Nguyen K. P. and Le V. T. - Studying and modeling impacts of climate change to natural, human, economic and social issues in Hochiminh city (in Vietnamese). Department of Science and Technology Hochiminh city, 2011.

10. Nguyen K. P. - Climate change and its impacts on Hochiminh city. Publisher: Vietnam National University - Ho Chi Minh City (in Vietnamese), 2012.

11. IPCC - Climate Change 2007: Synthesis Report - Summary for Policymakers, Assessment of Working Groups I, II and III to the Third Assessment Report of the IPCC, Cambridge University Press, 2007.

12. Nguyen T. S. and Can T. V. - The methods of assessing vulnerability. Theory and Practice. Part 1: Applicability in assessing vulnerability to floods in Central of Vietnam (in Vietnamese), Journal of Science. Vietnam National University, Hanoi: Natural Sciences and Technology 28 (3S) (2012) 115 - 122.

13. Thomas L. Saaty - The Analytic Hierarchy Process. New York, McGraw-Hill, 1980. 
14. Le Ngoc Tuan, Tran Xuan Hoang, Hoang Hung - Assessing exposure level to inundation of the rural fresh water and sanitation in Can Gio. Science and Technology Development Journal (in Vietnamese) (accepted).

15. Vu Thi Ngoc My, Le Ngoc Tuan - Assessing exposure level to saltwater intrusion of the rural fresh water and sanitation - a case study in Can Gio (in Vietnamese), The $19^{\text {th }}$ National conference of hydrology, meteorology, environment and climate change, Nov. 2016. 